\title{
Patrimonio y espacio público. La invención de la tolerancia (Perú, siglo XIX)
}

\section{Fernando Armas Asin}

Se ha afirmado que la transición a una sociedad más secularizada en la Europa del siglo XIX es quizás uno de los cambios ideológicos más profundos de la época contemporánea, en donde la religión, de ser elemento cohesionador y directivo, pasó a conformar un espacio limi-tado y cambiante en el ámbito del pensamiento humano ${ }^{8}$. El examen superficial que de ello se haga lleva irremediablemente a la búsqueda de sus orígenes en la lucha por la reforma religiosa, tolerancia, reforma social, la libertad política y el nacimiento de los movimientos liberales y radicales modernos, en los que se van gestando conceptos e ideologías cruciales que posibilitarán tal proceso. En ese sentido se puede afirmar que la tolerancia es hoy un espacio patrimonial de las sociedades foráneas.

Precisamente, dentro de este cúmulo de causas del fenómeno, se tiende a comprender que la tolerancia fue tal vez la que más influencia generó sobre el proceso, debido entre otras cosas a que su formación fue de la mano de la

\footnotetext{
${ }^{8}$ Por ejemplo entre los historiadores ingleses, ésa es la opinión de E Hobsbawm. Cf Las revoluciones burguesas. Madrid, Guadarrama 1975 p. 217.
}

irrupción secularizadora y del desarrollo de otro concepto esencial, el de libertad. En tal sentido, existe el consenso que la conformación de esta tolerancia es el resultado de la aceptación pragmática de la diversidad religiosa luego de esfuerzos infructuosos por eliminarla, y que tiene en Inglaterra su mejor exponente. Que luego sería retomado y desarrollado en un sentido político por los disidentes político- religiosos protestantes posteriores ${ }^{9}$, por el empirismo inglés y el liberalismo ilustrado del siglo XVIII. Más tarde llegarían la diversidad de corrientes liberales $y$ radicales modernas del XIX, que en un sentido programático buscarian desarrollar tales

\footnotetext{
${ }^{9}$ Es la perspectiva de Walzer, quien sostiene que la actividad impersonal, disciplinada y metódica de los partidos revolucionarios se remonta a Calvino y no a Maquiavelo. Dirá que: "los calvinistas fueron los primeros en trasladar el énfasis del pensamiento político del príncipe al santo (o la banda de santos...). Lo que dijeron los calvinistas acerca del santo, lo dirían más tarde otros sobre el ciudadano: el mismo sentido de virtudes cívicas, de disciplina y de deber... El diligente activismo de los santos -ginebrinos, hugonotes, alemanes, escoceses y puritanos determinó la transformación de política en trabajo", y, quizá lo más importante de todo, "tanto en política como en religión, los santos eran hombres de oposición y su tarea primordial era la destrucción del orden tradicional". De donde se colige que, aunque intolerantes religiosos al interior del grupo, a la larga, por virud del propio desarrollo de sus opciones en el medio, terminaron siendo vehículos de tolerancia en tanto disidentes y admitidos sociales, influenciando a su vez, éticamente, sobre la política. Michael Walzer, The Revolution of the Saints. London, 1966 pp. 2 y ss. También Cf. Ursula Henriques, Religious Toleration in England, 1787-1833 London, 1961.
} 
conceptos como base de una plataforma de cambio social.

En América Latina existieron estas corrientes radicales, de influjo liberal, aunque los intelectuales americanos abracen desde el inicio un claro liberalismo ilustrado de corte moderado que acepte la soberanía de la razón y las libertades individuales de libre realización, pero que no cuestione la tradición regalista de concebir a la religión católica y a la Iglesia como instrumentos al servicio de los hombres, representados en la figura del Estado. Va a ser a mediados de siglo, cuando los liberales latinoamericanos superen la etapa ilustrada anterior y se aboquen a una tarea de modernización de sus naciones basados en nuevos principios y conceptos. Influenciados por nuevos ideales europeos, leyendo a Lamennais, Cousin, Guizot, pasando por Fourier, de Leroux, Savigny, hasta llegar a Constant $e$ inclusive algunos a Hegel, abogarán por el necesario cambio en las naciones, por el cambio social y el nacimiento de una sociedad justa y liberal.

En todo este conjunto, el interés por la reforma liberal implicaba un serio ajuste en los términos de la relación con la Iglesia católica. Formados en una mentalidad económica librecambista y social descorporativa, no podían entender el proceso de modernización de la sociedad si no se entendía que finalizaba una serie de privilegios que detentaban las instituciones corporativas. La modernización de la sociedad empezaba con el establecimiento de una economía abierta a los mercados externos, lo que implicaba necesariamente modernizar la agricultura, donde el diezmo entorpecía su desarrollo; propiciando el movimiento de capitales, desamortizando capellanías y censos que inmovilizaban capitales e hipotecas y volvían el mercado inelástico; y sobre todo, eliminando los fueros privativos de la Iglesia, un estado dentro del estado, que en su óptica era un fuerte resabio que chocaba contra la modernización del país. Era una cuestión de fin práctico y económi$\mathrm{co}$, en los que conceptos como libertad y libre concurrencia pretendían imponerse sobre privilegios y exenciones. En tal sentido era previsible que la Iglesia debería resignarse a perder sus privilegios económico- judiciales. Por otro lado, la modernización, en tanto buscaba la regeneración nacional, que pasaba por la educación y la inmigración, también implicaba dar una serie de libertades básicas. Por ejemplo, el fin del monopolio educativo eclesial y el inicio de la educación pública. $Y$ en cuanto a la inmigración y su fomento, de anglosajones y germanos, la necesidad de tolerancia religiosa como imprescindible para su consecución ${ }^{10}$.

Ciertamente el mayor argumento que pusieron para lograr la tolerancia de cultos fue el fomento de la inmigración, y el crear un marco jurídico necesario para la libertad de sus prácticas. Lo que no solamente implicaba tolerancia religiosa sino, además, matrimonio civil (por lo menos de estos extranjeros), cementerios libres, etc. Pero no fue solamente ese el argumento. Mientras unos lo referían (los más impregnados por el pensamiento inmigracionista), otros defendían estas reformas basados en la libertad de conciencias, que no era otra cosa que el ideal caro de lograr la 'civilización' de los países. La libertad para ejercer libremente las creencias, los ideales ${ }^{11}$. Basados en principios libertarios 0 sobre la base de principios prácticos de inmigración, el liberalismo propugnaría la tan ansiada modernización. Un concepto concilió ambos fines, prácticos y doctrinarios: el Progreso. Para el liberalismo más extremo, todo progreso venía de los paises protestantes (tanto a nivel de tecnología como de libertades individuales). Creyeron que la inmigración era en verdad necesaria, y que las mayores barreras para lograrlo eran las leyes "retrógradas" y la Iglesia, enemiga número uno de la nación. Se planteó necesario europeizar América.

Habiéndose permitido hasta el momento el culto privado a los extranjeros, la urgencia de la inmigración obligará a que en algunos países la tolerancia legal empiece a practicarse ${ }^{12}$. Lo cual va a provocar una fuerte radicalización de los eclesiales, que a su vez se ven reforzados por un proceso internacional de Romanización que vivían. Los liberales, reagrupados en torno a la

\footnotetext{
${ }^{10}$ Había que procurar, por el cruzamiento de razas, el cruzamiento de la tradición hispano-criolla, y devolverle a la vida su antigua pureza y sentido espiritual. Y claro, pasaba por estimular la inmigración, vía condiciones propicias y tolerancia de sus prácticas. J.L. Romero, o.c. p 150.

"I $\mathrm{Sin}$ duda un reavivamiento había sido la publicación del texto de Vicente Rocafuerte, Ensayo sobre tolerancia religiosa (1831), editado en México y que impactó entre los liberales mexicanos, hasta ese momento no insertos en la polémica.

12 Para el caso de México puede leerse a Walther Bernecker, "Intolerancia religiosa e inmigración en México, siglo XIX". En: Cristianismo y Sociedad 99 (1989) 7-24. Para Pení una buena introducción es el artículo de Pilar Garća Jordán, "Progreso, inmigración y libertad de cultos en el Perí a mediados del siglo XIX". En Siglo XIX 3(1987) 37-61.
} 
idea de progreso e inmigración, se radicalizarán en un sentido anticatólico e incluso anticlerical13.

En el Perú instituciones como las iglesias protestantes, que desde 1886 empezaron a asentarse en el país, y la acción pública de las logias masónicas sobre el tema ${ }^{14}$, terminaron de dar fisonomía a un cuadro completamente nuevo, donde evidentemente se planteaba la tolerancia ${ }^{15}$.Grupos de liberales influenciados por variadas corrientes del positivismo, radicales liberales, anticlericales, anarquistas, socialistas, masones, protestantes, y descreídos. Todos, mostrando ser expresiones de una nueva sociedad, van a coincidir en esas propuestas. Por supuesto que frente a ellos la Iglesia católica debería reaccionar.

Uno de los hechos notables, casi a inicios del gobierno de Cáceres (1886), que enfrentó a los viejos y nuevos sectores portadores de ideales secularizadores y a los grupos católicos, dejando trasiucir una época cargada de fuerte conciencia modernizante, fue sin duda el problema que generó la publicación del texto escolar de historia del jesuita P. Ricardo Cappa, Historia

\footnotetext{
${ }^{13} \mathrm{Cf}$ Tulio Halperin D., El espejo de la historia, problemas argentinos y perspectivas latinoamericanas. Buenos Aires, Ed Sudamericana 1987 pp 17 38: Félix Weinberg, Las ideas sociales de Sarmiento. Buenos Aires, Eudeba, 1988 pp. 9-26. Este proyecto liberal también se halla ligado al desarrollo del espíritu de asociación que tanto esperaba promover Vicente Rocafuerte. J. Marichal, Cuatro fases de la historia intelectual latinoamericana. Madrid, S.A., 1978.

${ }^{14}$ Es bueno desde ahora entender que las Iglesias protestantes y las logias masónicas fueron, a fines del siglo XIX, espacios donde el credo liberal y radical logró adeptos, posibilitando que ambos ámbitos institucionales sean particularmente activos en la lucha por medidas secularizadoras. En las iglesias protestantes, el misionero extranjero, norteamericano sobre todo, fue portador de ideales modernizadores (en materia de educación, política, etc.) en tanto oriundo de una sociedad liberal y democrática. Trajo concepciones sobre el rol de la mujer en la sociedad, sobre el carácter democrático de las decisiones sociales, sobre el respeto a las leyes, etc, que ciertamente influenciarán en las nacientes Igiesias. No es de su propiedad, empero, y lo podemos visualizar en otros migrantes. Aquello, y el interés de su minoría por obtener la tolerancia de su accionar público, son la contraparte a la presencia del ideal libertario en su seno. Por una u otra vía fueron aliados institucionales de diversos sectores liberales y radicales. Algo análogo puede decirse de las logias masonas. Habían existido desde por lo menos 1807 , siendo connotados miembros muchos de los liberales ilustrados de las primeras décadas republicanas San Marún. Bolívar, F.J. Mariátegui-. Se trataba sobre todo de espacios de reflexión moral e intelectual, lo que hizo que incluso muchos eclesiásticos liberales participarao. Sin embargo la diversidad de ritos que segufan (yorkina, escocesa, alemana, italiana, etc.), la falta de reglamentos internos adecuados, y la carencia de federaciones que las aglutinara, hizo que languidecieran hacia 1830. En ese año las del rito escocés se unieron bajo El Gran Oriente Peruano. Sin embargo esta federación no tuvo la misma influencia sobre la política y el liberalismo de mediados de siglo, que, por ejemplo, la masonería imperial brasileña. En 1859 ocurre una escisión de logias adscritas a la federación, que crean El Supremo Consejo. El Gran Oriente en 1882 cambiará su nombre por la Gran Logia del Pení. A fines de siglo existen entonces dos federaciones del rito escocés -el rito mayoritario-, el Supremo Consejo (cuatro logias y 680 miembros) y la Gran Logia del Perú (cinco logias y trescientes miembros). Curiosamente será esta última la que dará mucho que
}

compendiada del Perú, en el cual se criticó severamente el movimiento emancipador y a los gobiernos republicanos, elogiando de paso la época colonial y su legado. La tradición educativa, forjada a la sombra de un liberal como S. Lorente, había logrado imprimir un cierto olvido del pasado español, de modo que el texto de Cappa, revalorizando el tema e incluso imprimiendo un aire apologético sobre la herencia hispánica, provocó el escándalo. Por supuesto que detrás se encontraba cierto desagrado percibido entre muchos sectores influyentes de la sociedad, ante la vuelta de los jesuitas y la apertura de colegios. La vieja bandera antijesuita pudo levantarse entonces a raíz de este caso. Ricardo Palma, uno de ellos, y anticlerical por excelencia, publicó un texto en el cual ponía en guardia "a los sectores lúcidos" contra la propaganda jesuita, que pretendía a través de la educación, destruir la obra "progresista"16. Sus razones despertaron a los amigos de Cappa, y los ataques contra él, a través de algunos diarios, no se hicieron esperar. Pero la adopción hecha por un Colegio de Lima del controvertido texto, y la posterior investigación periodística descubriendo que era de la Compañía, movieron a que liberales y anticlericales, temiendo la "avanzada antirrepublicana" en la educación, organizaran

hablar, pues estará implicada en la mayoría de las polémicas secularizadoras y por tolerancia de esos años. Está en estricta relación con el hecho fehaciente que mucho de sus miembros eran políticos e intelectuales liberales (R. Palma, Ch.Dam, W.R. Grace, F.J. Mariátegui, J.M. Químper, A. Deustua), que incluso tomaron el control directivo de la institución (César Canevaro fue Gran Maestro en 1887, Dam en 1896, etc). Haciendo que la federación participara activamente en las controversias secularizadoras. Produciendo otra alianza institucional. Cf. sobre la masonería peruana, Alejandro Alayza Paz Soldán, Breve historia de la francmasonería peruana y del pacto celebrado entre la Gran Logia del Perú y el Supremo Consejo del grado 33 del rito escocés. Lima, ed. Revista Masónica del Perú 1966; Eduardo Mendoza, La historia de la masonería en el Perú (t. ll República) Lima, ed. Tipográfica 1966; Carlos López Albújar, Masones y masonería en el Perú. Lima, Imp. del Politécnico Nacional José Pardo 1961. La visión católica en Lucien Johnson La Francmasonería (Trad. de Robert Frensen). Lima, Sanmart' 1953.

15Según El Almanaque de El Comercio (1897) pp 206-207, de los 100,194 limeños censados en 1896, 1,299 eran protestantes y 1,683 "idólatras". En 1856 , según Fuentes, sobre 94,195 limeños, apenas 386 eran protestantes y 262 eran confusionistas. Cf. M.A. Fuentes Estadística General de Lima. Lima, Tip. Nacional de M.N. Corpancho 1858, p. 621.

${ }^{16} \mathrm{Cf}$. Ricardo Palma, Refutación a un compendio de Historia del Perú Lima, Imp. Torres Aguirre 1886. Capítulo por capítulo refutó, "las más culminantes exageraciones, falsedades y calumnias de que tan profusamente está sembrada esa historia". Cappa había sido teniente de la Armada Española, y como tal participó en el combate del 2 de mayo. Luego de hacerse sacerdote llegó al Perí en 1878, publicando una Historia del Perí en tres tomos entre 1885 y 1886 (1885: Colón y los Españoles; 1886:La Conquista; 1887: Las Guerras Civiles y la Anarquía) que merecieron la solitaria reprobación de Eugenio Larrabure en una serie de artículos periodísticos, sobre todo por la apología parcial que hacía de los españoles en el descubrimiento y conquista, y la defenestración a la figura de Colón, sobre quien terminó recayendo la culpa histórica de la leyenda negra. La publicación escolar de 1886 era una síntesis de la obra mayor. Palma publicó su refutación en artículos aparecidos en El Nacional. Luego se editó como conjunto. Basadre Historia...,t. VI., PP 2938-2939. 
una serie de Grandes Mítines, el primero de los cuales se realizó el 17 de julio, con González Prada y otros elementos anticlericales, que pedían la salida de los religiosos. La prensa liberal y radical se hizo eco de esta polémica y también las logias masonas adscritas a la Gran Logia del Perú (Ricardo Palma era prominente miembro). Estas organizaron manifestaciones públicas en Lima, Callao, Trujillo, Moquegua, y Mollendo, pidiendo al presidente Cáceres detener la agresión jesuita "antipatriótica"17. El 26 de setiembre, en una reunión de más de dos mil personas, en el Teatro Politeama, redactaron un memorial al Presidente y el Congreso ${ }^{18}$. Así, liberales y radicales, utilizando a instituciones como las logias, hicieron pública su disconformidad. El tema de la obra de Cappa, su enfrentamiento a una tradición educativa liberal y nacionalista ${ }^{19}$, fue un motivo significativo para poder romper baterías contra el regreso de la Compañía en primer lugar, y contra los "vientos clericales" que soplaban en el ambiente. No es de extrañar que diversos elementos se hiciesen eco de esta necesidad, máxime si tenemos en cuenta el fuerte ánimo secularizador existente. El resultado de todo fue la segunda expulsión de la Compañía de Jesús, aquel mismo año. Sin embargo, a todas luces era evidente que el gobierno actuó presionado por las circunstancias, pues no tuvo mayor inconveniente en aceptar su regreso al año siguiente 20 . El más importante problema sobre tolerancia de cultos y actividad

${ }^{17} \mathrm{Cf}$. Carlos López Albújar, Masones y masonería en el Perú. Lima, imp. del Politécnico José Pardo (1961). La campaña estuvo dirigida por Ricardo Palma, Christian Dam, F.J. Mariátegui, José Gálvez, el gral. César Canevaro y Carlos Paz Soldán. No todos eran radicales y anticlericales como Palma y Dam. Carlos Paz Soldán, por ejemplo, se consideraba un liberal católico, pero percibja en los jesuitas el conservadurismo reurogado por excelencia. Augusto Ruiz Zevallos, Psiquiatras y locos. Entre la modernización contra los andes y el nuevo proyecto de modernidad. Perú $1850-1930$. Lima, Instituto Pasado y Presente 1994, p. 69. Mientras él era liberal anticivilista, Dam se mostraba anticlerical y en los límites hacia el anarquismo (que luego, como González Prada, lo cruzaría). Sobre sus ideas Cf. Ch. Dam, Breve reseña sobre la historia de los Jesuitas Lima, Imp. Liberal 1907, pp 22-23, narrando los sucesos de 1886.

$18 \mathrm{~A}$ la que asistieron no sólo masones, sino también otros liberales, radicales y anticlericales, que se movilizaron en pro de la expulsión. Previamente se habían reunido, el 4 de setiembre de 1886, todas las logias adscritas a la Federación, acordando unir esfuerzos con grupos liberales, y presionar al gobierno.

${ }^{19}$ Parece que los sectores liberales y radicales de tendencia anticlerical vieron en la actitud de Cappa una muestra del intento eclesial por abolir un modelo nacionalista de carácter antihispánico, forjado a lo largo del siglo, y que era uno de los baluartes más importantes del liberalismo educativo en el Perú.

${ }^{20} \mathrm{Cf}$. la versión jesuítica en, Compañáa de Jesús, Documentos históricos principales relativos a su expulsión Lima, Carlos Prince 1886; Jeffrey Klaiber,La Iglesia en el Perú. Lima, PUC 1988, cap III; Nieto Vélez. Historia del Colegio de la Inmaculada. Lima, 1978. El Congreso dio una ley interpretativa de la dada en 1856. Sobre Cappa, regresó a España y siguió publicando trabajos históricos de tendencia hispanista. protestante lo tenemos con el caso del metodista F. Penzotti, quien en 1890 mientras predicaba (efectuando por primera vez una labor evangelizadora no católica en el Perú) fue detenido por transgredir el artículo constitucional que lo prohibía expresamente. Fue la hora crucial para el protestantismo, una de esas pocas veces en que el Estado asumía per se el resguardo del artículo 4 , enfrentándose de lleno a los problemas que siempre había temido: los pleitos internacionales y la disminución de posibilidades para atraer inmigrantes al país. Habían sido los sectores católicos quienes provocaron esta situación. Entonces los partidarios de la tolerancia empezaron a acercarse a los metodistas para hacer causa común frente al tema. Ceder en este punto hubiera sido reconocer de facto la razón a los sectores católicos, marcar un precedente legal que ni los protestantes ni los liberales radicales, que iban levantando las banderas de la reforma del artículo 4, podían aceptar ${ }^{21}$.

Ciudadanos distinguidos y políticos llegaron a la cárcel a visitarlo. El 10 de octubre el político civilista Ricardo García Rosell habló ante el Senado pidiendo la tolerancia religiosa. "Ningún hombre creyente u honesto desembarcaría en nuestras costas si nosotros arrancáramos, al momento de su llegada, el libro que es su código de honor". Para él, proinmigracionista, "No vendría porque sería perseguido por tener creencias diferentes y practicar actos religiosos distintos a los nuestros"22. Al día siguiente, 11, lideró una manifestación exigiendo la tolerancia religiosa. En esa misma reunión Manuel González Prada y Eduardo Lavergne (el 9 de setiembre ya habian realizado otra) pidieron al gobierno la modificación del artículo 4, porque "es condición indispensable para el progreso de la

\footnotetext{
${ }^{2 !}$ Daniels,o.c., p 216. Para empezar, el estudio de Alberto Químper fue el encargado de llevar a cabo la defensa. Se comisionó a los abogados José María Vivanco y J.B. Ugarte. Todos liberales.

${ }^{22}$ Kulh, o.c., pp.51-52.

23"Exmo. Señor. Los que suscribimos, residentes del Perú, convencidos que es condición indispensable por el progreso de la Nación el respeto $\{$ las creencias de todo individuo, acudimos a V.E. á fin de que sirva tener en consideración esta solicitud y suprima la parte del art. 4 de la Constitución que establece que no se permite el ejercicio público de otra religión que la catolica, declarando que en lo sucesivo se garantice la libertad de creencias y la práctica de todo culto...". Memorial del 11-X-1890. Melchor Moya, La libertad de cultos en el Perú. Cuzco, Tip. Católica 1891, pp 19-20. Cabe mencionar que los liberales radicales serán claros en pedir la libertad y no la tolerancia de cuitos. El sentimiento católico se nos muestra en toda su esencia radical en Moya, al darle poca importancia (pero recogiéndola a la vez) la reunión del II de octubre en el que - según él - asistieron protestantes, budistas, mahometanos, judios, extranjeros y sólo 30 o 35 peruanos, intentando minimizar estas concentraciones. Por otro lado, el tema también caus 6 zozobra en el Congreso, donde se discutía un proyecto de ley sobre inmigración. García Rosell y otros parlamentarios lo atestiguan, aduciendo que el escándalo había estallado "justo en el momento en que el Perú busca la inmigración".
} 
Nación"23. Al mismo tiempo Pedro Ortiz publicaba su Libertad de Cultos argumentando que el momento era propicio para la reforma constitucional, para aligerar los obstáculos que encontraban los extranjeros en establecerse, para fomentar la inmigración, el progreso, "para salvar el porvenir del País, tan generoso como desgraciado... entonces y sólo entonces acudirán a nuestras playas los hombres de todos los climas, de todas las creencias, trayendo el precioso contingente de su laboriosidad, honradez y economía"24.

La radicalización, y el enfrentamiento de modernidad/tradición, se produjo. En las paredes del Callao se leía "Afuera los Protestantes!", "Mueran los liberales!", al lado de "Abajo los frailes, No queremos hombres con polleras!"25. Mientras una nueva manifestación de liberales del Callao a Lima, el 9 de noviembre, pedía la tolerancia26.

La polémica sobre inmigración y modernización se polarizó. La Gran Logia del Perú, que aglutinaba al mayor número de logias de masones, tenía entre sus miembros a prominentes políticos y profesionales liberales partidarios de la tolerancia27. Desde el inicio del caso, abogados suyos (José María Vivanco y José B. Ugarte) defendían a Penzotti:

"The brothers José María Vivanco and José B. Ugarte were named for the defense of the accused, the presbyter Penzotti, before the court of crime in Callao and the court of their capital, respectively. The first complicad with his missions with the zeal and talent that had won him credit in his noble profession; the second found it impossible to respond to the honour received, in beins named defense lawyn by the court, and this

\footnotetext{
${ }^{24}$ O.c.. p. 24.

25"Autobiografía de F.G. Penzotti", o.c., p. 214.

${ }^{26}$ Acta "...lero. Protestar de la manera como se ha procedido últimamente en los cornicios del Sur de la República, con motivo de la cuestion "Magdala", condenando los abusos y tragedias comctidos en dichos comicios. 2do. Pedir por el órgano regular a la Representación Nacional, que en la próxima legislatura proponga la variación del precepto constitucional religioso, en el sentido que se obtenga la tolerancia de cultos en toda la República..." Moya, o.c., p. 21.

${ }^{27}$ Por ejemplo Casimiro Medina, José B. Ugarte, José María Vivanco, políticos como Químper o Alejandro Deustua, inmigrantes como W.R. Grace, y sobre todo gran cantidad de inmigrantes italianos, lo que a su vez refuerza la explicación de la ayuda que la Gran Logia prestó a Penzotti. Más tarde Thomas Wood también sería prominente miembro. Habia liberales, protestantes, peruanos o extranjeros, políticos o empresarios, o simples profesionales. Cf. ALGDU Liminar de los Anales masónicos de las Resp....loq...SIMB...Concordia Universal número 14: apuntes sinópticos al conmemorar cien añus de su fundación. Callao, Talleres Gráficos Quiroz 1949, p. 79.
}

duty happily fell to Alberto Químper who has harverted insdmeasuable laurels with his brilliant presentation before the tribunals of justice in the difunde". ${ }^{28}$

No es de extrañar entonces que la Revista Masónica del Perú fuera otro palco de lucha. Alli Casimiro Melgar y el mismo José B. Ugarte serán implacables defensores libertarios 29 . Mientras que diversos masones participen en los mítines organizados en el Callao. En medio de toda esta presión, el 29 de noviembre el juez en lo civil, Dr. Nicomedes Porras, absolvió en primera instancia a Penzotti. Luego, en el verano de 1891 sería absuelto totalmente.

Aparte del caso Penzotti, el obispo de Trujillo logrará que un predicador llamado Abrill sea arrestado en esa ciudad bajo los mismos cargos hechos a Penzotti, pero se fallará a su favor en primera instancia ${ }^{30}$. En Ayacucho, en 1893, un vendedor de biblias es asediado por una multitud, que le quita sus pertenencias y las incinera en la Plaza de Armas. En Lima mismo Thomás Wood, el sucesor de Penzotti al frente del metodismo, masón de trigésimo segundo grado, tendrá problemas durante el gobierno de Piérola, cuando algunas de sus escuelas sean cerradas, se detengan remesas de biblias, se prohíba la visita casa por casa y en 1899 , durante la semana de Oración Universal, se le arreste en medio de un sermón por haber celebrado cultos todos los días de la semana ${ }^{31}$. Son problemas que evidencian que los protestantes pasaron rápidamente a

\footnotetext{
${ }^{28}$ Sección Oficial. Revista Masónica del Perú. Lima, marzo 31 (1891)X, 113 p. 189. Cit. Tr. al inglés Bruno Jof-fréo.c. En la misma revista y sección se pide la reforma del artículo 4, p 58. Por otro lado, el abogado litigante de Penzotti era Pablo Mora, del estudio Alberto Químper Gaceta Judicial Lima,2 de setiembre de 1891.

${ }^{29} \mathrm{Cf}$ "Dictámenes" En: Revista Masónica Lima, marzo 31 (1892)X1 p. 125. La revista pedirá sin tapujos la reforma del artículo 4. Cf "Sección Oficial" En: Revista Masónica. Lima, marzo 31 (1891)X 113, p. 58.

${ }^{30}$ El Cristiano, Lima, Junio de 1921, p 87 . Renacimiento. Lima, agosto de 1921, p 119. Era miembro de la RBMU y fue acusado por un sacerdote debido a que, vendiendo biblias de casa en casa, contravenía la Constitución. Stark (uno de los jóvenes del Harley College y miembro de la RBMU) se traslado a Trujillo para ayudarlo, pero no hubo mayor necesidad pues en primera instancia se le absolvió. El vender biblias no era delito, sino el predicar. Este fallo se debió al mal planteamien. to de la acusación.

31 Actas de la Segunda Reunión de la Conferencia Misionera Occidental de Sudamérica de la Iglesia Metodista Episcopal. Santiago 15-20 de febrero de 1899. p 30. Cit por Kessler, o.c. p 101. Ciertamente cada uno de estos hechos tienen su contorno peculiar. Algunos colegios son cerrados por problemas de cuestiones adminisurativas y quejas de adoctrinamiento que hacen algunos sacerdotes del Callao. La predicación de casa en casa es prohibida, debido a las presiones de sectores catolicos. El tema no levanta polvareda en tanto no se cuestiona directamente la tolerancia implícita de predicación. El mismo arresto de 1890 es sólo simbólico, y Wood es rápidamente puesto en libertad. Hay que entender, detrás de todo, la presión ejercida sobre el gobierno y el eco que encuentran los sectores católicos en él. por una parte, pero además entender que fueron hechos poco significativos teniendo en cuenta el prestigio de la figura de Wood, y el hecho que esos sucesos (los arrestos) eran cada vez más raros en Lima.
} 
convertirse en centro como liberales y radicales políticos de los ataques católicos. La lucha contra la impiedad exigía que los enemigos de la Iglesia fuesen permanentemente obstaculizados, que fuesen denunciados desde el púlpito y frente al juez, aun a pesar de entenderse que a muchos gobiernos poco o nada les interesaba ayudarles.

Como los protestantes, también los masones son objetos de la diatriba. El 20 de abril de 1890, una muchedumbre católica asalta en Mollendo la casa templo donde se velaban los restos del senador Cazorla, ex maestro de la logia local. El ataque degenera en turba, y luego del destrozo del lugar, se dedican al saqueo de tiendas e incendios de casas de conocidos liberales. Luego atacan el Consulado norteamericano, donde tras un tiroteo, el cónsul cae herido en una pierna ${ }^{32}$. En 1892, los cuerpos de un inglés en Puno y un estadounidense en Piura, son impedidos de ser enterrados por el clero, en los cementerios respectivos. Condenados por León XIII en 1884, los masones peruanos atraen la atención33. Para Juan Ambrosio Huerta o Manuel Bandini (obispos entonces, de Arequipa y Lima), la masonería movía los hilos de la desintegración del Perú. Alertaban sobre su perfecta unión, por intereses anticatólicos, con el liberalismo. Huerta será más explícito, y a propósito de la ayuda de un sacerdote a Penzotti en Arequipa, dirá que los liberales son en el fondo masones ${ }^{34}$. Entenderá (como ya lo había expresado en su carta de 1884) que la lucha contra liberales y masones no es distinta, pues en su óptica la masonería le da el sustento espiritual que necesita el liberalismo, per se anticlerical. Sin distinguir dos instancias que pueden y tienen algunos intereses comunes por vínculos diversos, Huerta hablará que en el fondo el peligro primero del Perú es la masonería. En su Carta Pastoral... que traza a los católicos de su diócesis la conducta que tócales seguir en la lucha provocada por los masones del Perú del 15 de octubre de

\footnotetext{
${ }^{32} \mathrm{Cf}$. la posición católica en Manifiesto del Pueblo de Mollendo. Abril 20 de 1893. Arequipa, El Deber 1893. Argumentan que atacaron el recinto masón al amparo del art. 100 del Código Penal, que prohibe actos no católicos, bajo pena de prisión. Se muestran conformes con la intolerancia religiosa.

${ }^{33}$ León XIII, Humanum Genus Lima, Imp de Francisco Solls 1884. Cf., por ejemplo, los escritos católicos que van apareciendo sobre el tema, Diana Waughan Grandes revelaciones de los secretos y misterios de la masonería Lima, Imp. Católica 1891: Ramón Nocedal, Causa Célebre, Discurso de... sobre la masonería, seguido de importante revelación que con sagacidad oculta. Lima, Tip. Católica 1891; Anónimo, Refutación de la protesta de la masonería del Perú, contra las declaraciones de la Encíclica de S.S. León XIII por J.O.P. (EI Deber). Lima, Imp. de Francisco Solís 1885.

${ }^{34} \mathrm{Cf}$ Exhortación Pastoral...de 1891
}

1886 dirá que la ley en debate entonces, sobre cementerios laicos, como los otros problemas que cuestionan la unidad religiosa del Perú en el fondo sólo son una campaña montada por la masonería, que manipula a políticos, anticlericales y descreídos, utilizándolos para sus bajos fines destructivos de la sociedad católica. Lo volverá a repetir en 1896, en plena discusión de la ley de matrimonio de no católicos, recogiendo una hoja volante del 25 de setiembre de ese año donde la Gran Logia del Perú convocaba a una charla sobre el tema. Argumentará entonces, en su Carta Pastoral, que la masonería es ya un enemigo formidable del catolicismo en el Perú35.

Así, al lado de liberales y anticlericales se van agregando masones y protestantes en la larga lista de enemigos de la catolicidad del Perú. Se les rechaza, se les critica. No hay pastoral donde no se haga mención en este punto del gran peligro que entraña, para el futuro del país, dejarse llevar por tales ideas, que conducen a la disolución del orden y el fin de la nación. En el fondo el discurso, que se va nutriendo de los hechos de aquellos años, incorpora nuevos y novedosos enemigos a la Iglesia, pero no le interesa mayormente analizar las relaciones objetivas que existen entre estos grupos, sus intereses, etc. Escritas al calor de las coyunturas, cartas pastorales y hojas volantes, nos los pintan como aquella "sarta de herejes, degenerados, enemigos de Cristo y amigos del diablo" que pretenden imponer contra la voluntad de "todos los peruanos, que son católicos" ideas foráneas y exóticas, pues esas ideas no son las peruanas, que son las católicas. Así políticos liberales, extranjeros protestantes, masones, etc., son vistos bajo el cristal que los convierte en un conjunto peligroso para la Iglesia. Nadie entiende ni explica por qué los protestantes se dejan aliar con los políticos liberales y por qué éstos son muy entusiastas en apoyar a los protestantes, aun siendo no creyentes, y por qué grupos de masones participan en tales coyunturas. No entienden por qué se produce esa suerte de unión, que moviliza a instituciones y grupos diversos, alrededor del tema de tolerancia de cultos. Sólo entienden que la unión es anticatólica por naturaleza.

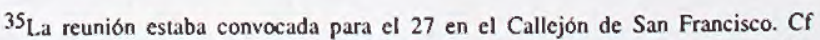
Huerta, Carta Pastoral... sobre matrimonio civil Lima, Lib. e Imp. San Pablo 1896.
} 
Conforme se llega al fin de siglo y se inicia el siglo XX, el liberalismo dejará de ser la vanguardia frente al conservadurismo religioso, alzándose otros sectores políticos y sociales. Por supuesto que en cualquier caso estamos hablando de una tolerancia de cultos que ante todo era una lucha más legal que objetiva, pues como lo expresaban sus propios propugnadores, y en cierto modo la Iglesia lo corroboraba, ya era practicada sobre todo por extranjeros y radicales nacionales mucho antes que estas leyes se intentaran siquiera plasmar 36 .

\title{
Conclusión
}

Alrededor de un tema como la lucha por la implantación de la tolerancia religiosa (base teórica de un proceso de modernización social), se ha revisado cómo esta lucha lleva inexorablemente a enfrentamientos entre el liberalismo (que muestra signos radicales) con la Iglesia. Asimismo, se ha revisado cómo diversos grupos de modernidad (iglesias protestantes, logias masónicas) influenciadas por la ideología liberal prestan apoyo al liberalismo político en su lucha por afirmar una sociedad más plural y abrir nuevos espacios de ruptura entre tradición y modernidad. Son en el fondo espacios de reflexión político - sociales interesantes. Lo cual los hace especialmente ricos para la reflexión sobre relaciones entre grupos de modernidad y la lucha por afirmar sus ideales.

\author{
Fernando Armas Asin \\ Facultad Turismo \\ Universidad San Martín de Porres \\ Lima, Perú \\ farmas@mixmail.com
}

\footnotetext{
${ }^{36} \mathrm{La}$ tolerancia legal se plasm6 finalmente en 1915. Cf. nuestro libro Fernando Armas Asin, Liberales, protestantes y masones. Tolerancia y Modernidad en el Perú del siglo XIX. Lima, PUCP.CBC 1998.
} 